\title{
Leh Symposium 2012 and PVRI India Annual Symposium
}

\author{
Pasha, Qadar ; Gassmann, Max ; Mohammad, Ghulam ; Haworth, Sheila G
}

DOI: https://doi.org/10.1089/ham.2012.1344

Posted at the Zurich Open Repository and Archive, University of Zurich ZORA URL: https://doi.org/10.5167/uzh-71088

Journal Article

Originally published at:

Pasha, Qadar; Gassmann, Max; Mohammad, Ghulam; Haworth, Sheila G (2012). Leh Symposium 2012 and PVRI India Annual Symposium. High Altitude Medicine Biology, 13(4):293-294.

DOI: https://doi.org/10.1089/ham.2012.1344 


\title{
Leh Symposium 2012 and PVRI India Annual Symposium
}

\author{
Qadar Pasha, ${ }^{1}$ Max Gassmann, ${ }^{2}$ Ghulam Mohammad, ${ }^{3}$ and Sheila G Haworth ${ }^{4}$
}

T He SECOND InTERnAtional Leh symposium 2012, which focused on "The Lung at High Altitude: From Cellular Acclimatization to Clinical Disease," and the PVRI (Pulmonary Vascular Research Institute) India annual meeting were organized in Leh, Ladakh. The city is situated at an altitude of about $3500 \mathrm{~m}$ above sea level within a beautiful valley of the great Himalayas. On the first day, apart from acclimatization to this challenging altitude, the PVRI India executive committee meeting was held. It was followed that evening by the scientific inauguration of the symposium. The subsequent three days harbored fifteen intensive scientific sessions that addressed the most relevant topics associated with altitude and hypoxia. The main topics involved genetics, the physiology of high altitude, pulmonary arterial hypertension (PAH), both the clinical and therapeutic aspects, and the influence of high altitude on the management of diseases other than PAH. The clinical sessions included neonatal, pediatric and adult PAH at altitude, both in the Himalayas and the Andes. Each session ended with a dedicated discussion resulting in fruitful interactions between speakers and audience.

\section{The Science in Himalayas}

Physical performance, adaptation and maladaptation leading to high-altitude disorders like high-altitude pulmonary edema (HAPE) and chronic mountain sickness (CMS) were attributed to the multifaceted impact of several factors including erythropoietin and to their genetic representation in individuals or in a community. Genetics of EGLN1, NADPH oxidase $p 22$ phox and BMPR2 were discussed at length. This was very well supported by metabolic modifications, variations in the levels of a number of circulating biomarkers including 8-isoprostaglandin, endothelin, serotonin, and the clinical parameters such as arterial oxygen and mean arterial pressure. Oxygen sensing in an hypobaric hypoxic environment highlighted the impact of the hypoxia-inducible factors (HIFs) and provided a solid basis against which to discuss the significance of various molecules involved in the oxygen sensing pathway. Moreover, variation in the oxygen sensing genes pointed to the natural selection of various traits in both Andean and Himalayan populations that has enabled them to adapt to extreme environment, whereas not all of the sojourners can cope with this harsh condition. Several presentations on therapeutics and the role of new drug-targets in disease management complemented the basic research presentations. Apart from human research, the mouse, rat, zebra fish and drosophila fly models provided ideal complementation, suggesting that different models can be used to unravel some human physiological functions which it may not be possible to explore directly in man.

It was inspiring to note that other diseases that are influenced by hypoxia and UV radiation were included in this symposium. Among these, skin diseases, asthma, chronic obstructive pulmonary disease (COPD), cancer and lung infection were prominently discussed. Likewise, anesthesia management was yet another focus of this symposium.

\section{Young Researchers' Contribution}

The highlight of this symposium was the active and enthusiastic participation of a remarkable number of young researchers in the proceedings. Each session has at least one young researcher presenting her/his work. A poster session was held in which the investigators show-cased their research activities. Out of these posters, four were selected for oral presentation. Each presenter was felicitated with a cash award, in addition to the best oral presention award. Various travel grants were awarded, the registration fee was waived and even local hospitality was provided to the young investigators in order to enable them to participate in this symposium. As a result a good number of young investigators could join us and surely benefitted by interacting with seniors and experts of the field. We expect that the intense interactions among the delegates will result in new collaborations.

\section{Encouragement and Support}

The encouragement to organize the symposium and the active participation of CSIR-IGIB, DST India, SNM hospital, ICMR and other Indian organizations as well as of the Pulmonary Vascular Research Institute (PVRI), the University of Zurich and the Zurich Center for Integrative Human Physiology (ZIHP), the European Respiration Society (ERS) and the Excellence Cluster Cardio-Pulmonary System (ECCPS), was gratefully acknowledged by the delegates. In addition, there were other sponsors who have been very supportive of this symposium among them SWISSNEX India that has been

\footnotetext{
${ }^{1}$ CSIR-Institute of Genomics and Integrative Biology, Delhi.

${ }^{2}$ Institute of Veterinary Physiology, Vetsuisse Faculty, and Zurich Center for Integrative Human Physiology (ZIHP), University of Zurich, Zurich.

${ }^{3}$ SNM hospital, Leh.

${ }^{4}$ University College London, London.
} 
in the forefront from the very beginning. From India, $M / s$ Agilent technologies, Premas Biotech, GenAxy and NFBGR were highly instrumental; the representatives of these companies even attended the symposium, interacted with the delegates, and several of them delivered talks.

The valedictory function reiterated the need of a research center at Leh. In this regard, the Council of Scientific and
Industrial Research and Indian Council of Medical Research, Delhi showed willingness to support such a research center. The task will soon be taken up with these Councils. This center, if established, would cater to the needs of the research activities of this region and would facilitate national and international collaborations with the faculty of SNM and other hospitals in the region. 